\title{
Private cannabis clinics offer clients access
}

$\mathrm{T}$ here's a budding business in the medical marijuana industry lurking between pot dispensaries and doctors' offices. Cannabis clinics connect people with physicians willing to prescribe legal access to medical marijuana - for a fee, of course.

The "prescription" is actually a Health Canada form that has to be filled out by a physician, but many doctors resent being gatekeepers to what they consider to be an unproven drug.

At least 25 clinics have sprung up in British Columbia, Alberta, Quebec, Ontario and possibly elsewhere. For people who qualify for medical marijuana and want to try it, these businesses claim to be the missing link in the system. Membership fees range from $\$ 99$ to $\$ 300$.

At National Access Cannabis in Ottawa, marijuana-savvy staff wearing black scrubs welcome clients to a facility that is decorated with the crisp simplicity of an Apple store: hardwood floors, white walls, white tables with green accented chairs, information boards and a glass case displaying a collection of vapourizers.

In the back corner are two private rooms enclosed by glass and hidden behind blinds, where the telemedicine conferences take place between the clinic's members and physicians who decide if the patient qualifies for the medical declaration to access marijuana as per Health Canada's Medical Marihuana (sic) for Medical Purposes Regulations (MMPR).

National Access Cannabis CEO Gulwant Bajwa, the former manager for Health Canada's Marihuana (sic) Medical Access Regulations, left after that program became invalid in March 2014. He says his business is "educating people on the use of cannabis so that they can make safe, and informed, and most importantly a responsible decision."

Members get access to the staff "pharmacist" - actually an international medical graduate - who asks them to provide medical documents including a

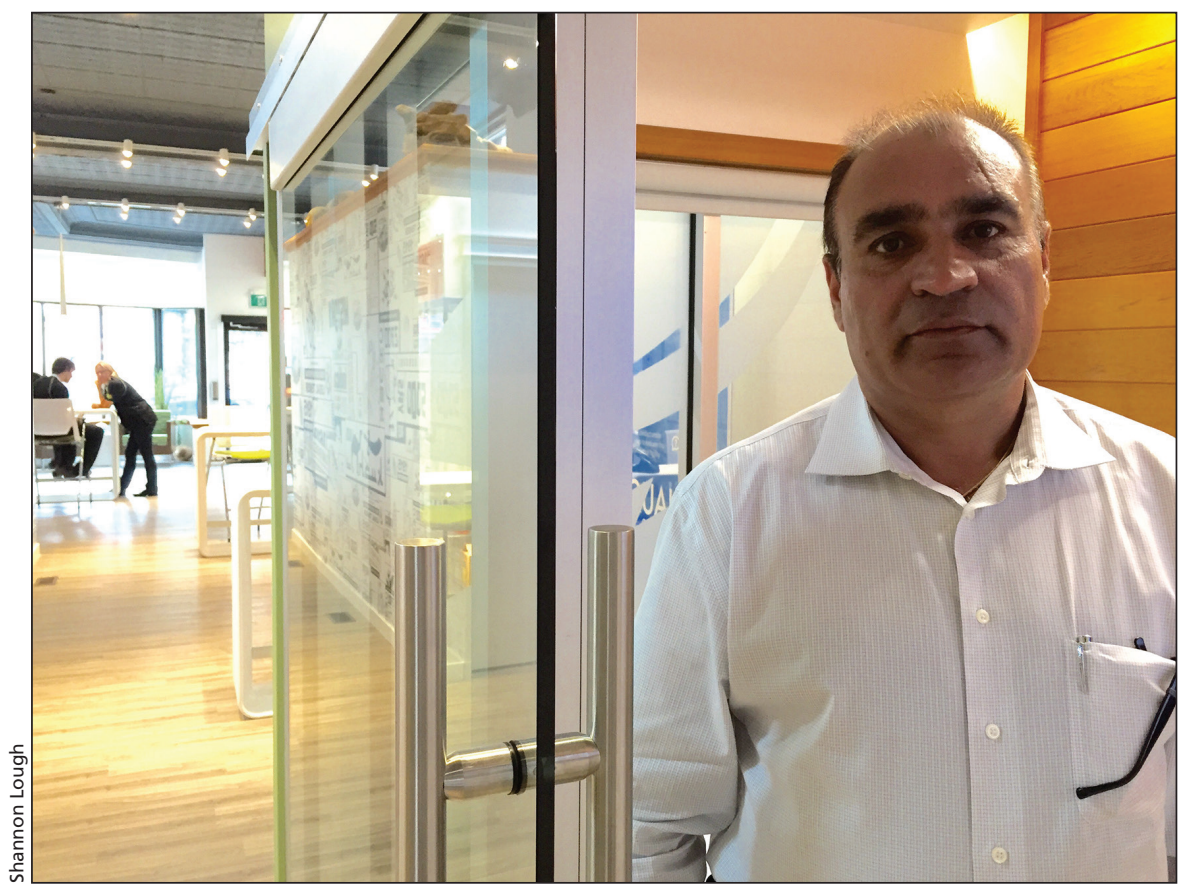

National Access Cannabis CEO Gulwant Bajwa says, "We don't want people to go to the street. We want them to get the medicine from a legal source supply."

letter of diagnosis from a physician, and copies of prescriptions and hospital records before arranging a telemedicine conference, for an additional $\$ 150$, with a physician. If the physician prescribes access to medical cannabis, the clinic staff help the member select the best strain for their condition from those offered by Canada's 19 licensed producers. They also instruct members on ways to consume the drug and use a software system to monitor the drug usage and interaction with other prescriptions.

"We don't want people to go to the street. We want them to get the medicine from a legal source supply," Bajwa says. He says his business is not commercially linked to any of the licensed producers.

There appears to be a growing demand for these businesses. As of March of this year, Health Canada reported that more than 18500 people had legal access to medical marijuana, but that doesn't include people grandfathered in through the previous medicinal marijuana program. The number of people with access is expected to reach
500000 in the next few years (Int $J$ Drug Policy 2015;26:15-19).

In a needs assessment survey by mdBriefCase, an online continuing medical education provider, 321 family doctors were asked how likely they are to prescribe access to medical marijuana: $8 \%$ say they currently prescribe, $32 \%$ say they might, $60 \%$ say it is unlikely they will prescribe.

This is where the intermediary approach comes in. Physicians willing to prescribe can provide services to clinics like National Access Cannabis either via telemedicine or off-site at their own clinics. To encourage more physicians to become familiar with the alternative treatment, National Access Cannabis has paid $\$ 995$ for 300 placements for the online Advancing Practice - Medical Cannabis Certificate Program, which is accredited by the Canadian Council on Continuing Education in Pharmacy.

"We actually want to work with Health Canada and we want to work with the regulatory agencies to give them an alternative. Come and have a 
look at our model, maybe this will work," Bajwa says.

Many of the clinics have opened in the year since the MMPR came into effect and each operates differently depending on provincial college policies.

In Ontario, for example, health practitioners must follow the College of Physicians and Surgeon's policy on prescribing medicinal marijuana, which
Other provincial colleges appear to be more concerned about the use of telemedicine than payment.

In British Columbia, the college's new rules around when telemedicine is appropriate, stipulate that the physician must have a long-term relationship with the patient, or be in direct communication with another physician or nurse practitioner who has such a relationship.

\section{"Health Canada has put the burden on doctors to prescribe and most of them are not willing to prescribe...."}

approves of telemedicine as long as the physician complies with the policy. But as for charging patients for a consultation, Ontario college spokesperson, Kathryn Clarke says the policy is clear: "Physicians must not charge patients or licensed producers of dried marijuana for completing the medical document, or for any activities associated with completing the medical document." According to Bajwa the fee charged by his clinic for the physician consultation goes to National Access Cannabis, not the physician.

Other clinic owners say that some doctors charge a "risk compensation." Recently, the College of Physicians and Surgeons of Manitoba began investigating reports that a doctor is charging $\$ 300$ a note to buy medical marijuana at a Winnipeg dispensary.
The registrar for the College of Physicians and Surgeons of British Columbia, Dr. Heidi Oetter, says "our caution around doing it by telemedicine simply reflects the fact that we think it's a service that's best provided face to face." She adds, "It's the one-offs that we're concerned about."

Prince Edward Island's college also prohibits physicians from using the medical document to prescribe marijuana through telemedicine. Dr. Cyril Moyse, the registrar of the PEI College of Physicians and Surgeons, says "one of the issues is that you have to continue to monitor the patient for effectiveness."

Not all the cannabis clinics use telemedicine. Pauline Garrard, the CEO of Canna Relief Consulting Canada in Mississauga, Ont. says she found it unreliable. "We want to stay on the straight and narrow and doing all the required things that keep the doctors safe and that keeps us safe. We just want to make sure we do the right thing for patients."

At her one-year-old clinic, staff educate and help clients sort their documents. If a member's physician will prescribe the drug, membership costs $\$ 150$; if not, the fee is $\$ 300$, which includes finding a physician who will meet the client at an off-site clinic.

"The whole obstacle is that Health Canada has put the burden on doctors to prescribe and most of them are not willing to prescribe because they don't have the information. So patients are the ones who lose because they don't have access," Garrard says.

In Vancouver, Medicinal Cannabis Resource Centre Inc., which opened in 2010, claims to be the first such clinic. It offers a hybrid of telemedicine and off-site clinics. The annual membership fee is $\$ 275$, walk-in appointments at an off-site clinic are \$275, and Skype consultations cost $\$ 375$.

CEO Terry Roycroft says "Physicians that have entrepreneurial spirit are looking at it as a new way to create a specialty line. - Shannon Lough, CMAJ

This is part one of a two-part series on medical cannabis clinics. Coming up: another clinic model is emerging that won't cost the patient a dime.

CMAJ 2015. DOI:10.1503/cmaj.109-5119

\section{New CMA president tackles demographic issues}

$\mathrm{W}$ ith the early call for a federal election, new CMA President Dr. Cindy Forbes hit the road running - at a pace that threatens to continue all year. Not that it will faze Forbes. As a runner and competitive paddler, the 56-year-old family physician from Waverley, Nova Scotia, knows about endurance. And she also knows medical politics after 30 years in the fray, beginning in medical school.

First up on her agenda is making the strategy for seniors' health care a pivotal election issue, not only to prepare for the future but also to ensure the survival of Canada's health system. Over$65 \mathrm{ers}$ already account for nearly half of health spending; by 2031, their number will double and the load will threaten the entire system.

"We'll be asking [the new government] to call a first ministers' meeting on the seniors' strategy within 60 days of their mandate," says Forbes, who began her term Aug. 26. "That's our main focus, but we're really looking for the federal government to get back into the health care."
The gap in federal attention is apparent in myriad ways, including the lack of impetus in establishing rules for physician-assisted dying, which are due in February. CMA will continue working on that thorny issue under Forbes. "CMA has been in the lead in bringing the physician voice to those discussions," says the Halifax-born Forbes.

Professionalism, pharmacare and medicinal marijuana may also be on her agenda. And it's going to be a busy year at CMA itself, with decisions on 